\title{
NO LLORES POR ÉL ARGENTINA (LUCHA DE CLASES VERSUS POPULISMO).
}

\section{PEDRO MORAGUES MOLINA}

\section{PRESENTACIÓN}

Al abordar este tema he creído suficiente, en un primer momento, dar cuenta de los elementos comunes que he encontrado entre los distintos autores; aquellas características, escasas, que ningún autor cuestiona como elementos constitutivos del populismo. Tratar de apuntar -de mi propia cosecha- elementos nuevos, creo que darían lugar a una mayor confusión.

En un segundo momento, después de dar cuenta de los aspectos esenciales del populismo, intentaré hacer otra aproximación al tema desde el concepto de clase. Creo que la aproximación crítica al populismo desde la clase puede resultar interesante por cuanto la pertinencia de ésta evidenciaría la falacia populista del pueblo como comunidad nacional. Por otro lado, el reconocimiento de la clase constituiría la clave para distinguir un movimiento populista de otro, digamos, revolucionario que compartiera algunas características propias del primero.

La elaboración de estos dos pasos pueden formar un cuadro suficientemente completo para el objeto que me propongo en este trabajo: una aproximación crítica y, si me apuran, subjetiva, ética y moral, al tema.

¿Por qué plantear el tema como aproximación crítico-subjetiva?. Varias razones me mueven a ello. En primer lugar, la línea que separa la objetividad científica de la subjetividad, el interés o la ideología, es tenue. Hay mucho trabajo científico que, tras esta etiqueta, esconde una profunda complicidad con el orden de cosas establecido; una especie de inercia científica conduce indefectiblemente a la defensa y/o justificación -a veces virulenta- de este orden de cosas. Opino que el científico, también -o sobre todo- el científico social, debe estar atento para procurar no contaminar su trabajo de sus propios intereses o ideología, pero también debe estar atento para procurar que la objetividad científica con la que se quiere adomar no se convierta en una coartada para justificar el statu quo. Coartada que no sólo justifica lo existente, sino que también cercena en el científico su capacidad creadora, aventurera, imaginativa, provocadora.

Por tanto, la primera razón no es otra que la confesada parcialidad desde la que abordo el asunto, confesión que me va a permitir no andar con rodeos, ni tratar de disfrazar de objetividad la propia ideología. Todo ésto sin detrimento de los mínimos requisitos que exige la elaboración de un trabajo serio, condición sine qua non para distinguir una crítica científica de una crítica ideológica o de la mera palabrería. 
En segundo lugar, es una buena excusa para seguir reafirmando por encima de populismos, la objetividad de los intereses de clase que se enfrentan en las sociedades capitalistas. Ayer, como hoy, la confrontación de los intereses de clases siguen siendo, a mi juicio, la división fundamental que atraviesa la sociedad y la lucha de clases el motor que debe alimentar el cambio económico y social. Luego entraré más a fondo en estas cuestiones.

En tercer lugar, porque en la actualidad viene muy al caso no sólo el asunto del trabajo, el populismo, sino la forma de enfrentarlo -críticamente-. En el momento presente parece que estamos viviendo un preocupante rebrotar de cierto tipo de populismo, no sólo en Latinoamérica, sino en buena parte del mundo: aparecen por todas partes los Berlusconi, los Yeltsin, los Gil, los Nemen, los Fujimori, podríamos decir incluso los González (Felipe) o los Díaz (el alcalde de mi pueblo). ¿Tienen todos éstos -y lo que ellos representan- algo en común además de un cierto liderazgo carismático?, ¿es sólo un estilo político que está en boga en nuestros días o son la punta de iceberg de unos movimientos hoy latentes, pero que pueden cristalizar en cualquier momento y de cualquier manera?, ¿cuáles sí, cuáles no?, etc..

Se ha hablado durante largo tiempo de la crisis de partidos, de los nuevos movimientos sociales, de ciertos experimentos a medio camino entre movimiento y partido (la reconversión del PCI o el intento de IU en España, incluso, en otro plano, los Verdes en Alemania), etc.. Parecía que los últimos iban a tomar el relevo a los primeros, pero poco se cayó en la cuenta del resurgimiento, en estos impasses políticos, de los líderes antipartidos, de populismos de nuevo cuño que si bien en el momento presente no han tomado formas autoritarias (salvapatrias) no quita que en el futuro, ante un agravamiento de la crisis económica u otras coyunturas políticas adversas y la identificación de un enemigo real o ficticio al que acusar de todos nuestros males, podamos asistir a nuevos movimientos de masas, a grandes concentraciones, a largos discursos de líderes carismáticos, a intentos de reversiones autoritarias, a violencias callejeras y/o institucionales, etc..

\section{EL POPULISMO DISCUSION TEORICA}

El trabajo, pues, lo voy a estructurar de la siguiente manera. En primer lugar, intentaré una aproximación al concepto, dando cuenta de los rasgos más característicos que han señalado -y en los que coinciden- los distintos autores que he podido consultar para realizar este trabajo.

En segundo lugar, intentaré -como dije en la presentación- una aproximación crítica del populismo desde la categoría de clase.

Ya en la segunda parte de este trabajo, intentaré abordar el estudio del fenómeno populista en la Argentina peronista, dentro del contexto latinoamericano. Finalmente, apuntaré unas breves conclusiones. 


\subsection{El populismo. Definición y rasgos}

Igual hubiera sido más apropiado intitular este apartado de una forma menos pretenciosa; algo así como "Populismo. Intento de definición y 'parecidos de familia'» porque de populistas han sido tachados fenómenos históricos muy diversos (1) y se han propuesto más de una tipología en las que se recogían casos realmente dispares entre sí (2). Esto da idea de la dificultad de ofrecer una definición lo suficientemente amplia como para dar cabida a todos esos fenómenos y, al mismo tiempo, lo suficientemente acotada para discriminar con claridad aquello que se puede etiquetar, efectivamente, como «El populismo es una de las ideologías políticas de mása difícil delimitación .../... Otro factor a tener en cuenta es que no todos los autores se ponen de acuerdo a la hora de definir a un determinado movimiento como «populista» (3).

Aunque todos los autores abundan en la dificultad de la definición del concepto, insisten en utilizarlo y en aplicárselo a distintos fenómenos sociopolíticos. Quiere esto decir que el concepto sigue siendo perfectamente operativo hoy día y no sólo el concepto: el fenómeno mismo, como decía en la presentación de este trabajo, parece estar cobrando una vigencia extraordinaria en muchos lugares del planeta.

La vigencia del fenómeno es un argumento más en favor de la necesidad de afinar su definición. En la actualidad es una especie de cajón de sastre donde cabe todo aquello que: a) no tiene cabida en otros conceptos y b) tiene cierto "parecido de familia» con otros fenómenos que sí pueden ser considerados plenamente populistas. Esto puede conducir a errores que pueden tener graves consecuencias, no ya científicas sino políticas, económicas y sociales. Para Atilio Boron, por ejemplo, es una cuestión fundamental saber caracterizar adecuadamente los regímenes políticos. Refiriéndose a los regímenes militares de América Latina, dice:

La identificación inexacta de la naturaleza de los regímenes militares en América Latina conlleva fatalmente a la incapacidad para discriminar aliados de adversarios. La necesidad de un rigurosa caracterización no se funda, por esto mismo, en un mero prurito academicista sino en una exigencia impuesta por la coyuntura política vigente (4).

Por lo tanto -y contra el parecer de Ipola (5) -creo necesario una acotación más estricta del término que deje fuera toda una serie de fenómenos y movimientos que, a duras penas, pueden ser catalogados como populistas y para los que quizá hubiera que inventar otro concepto que los definiera más apropiadamente.

Dicho esto, tengo que aclarar que no va a ser mi objetivo tratar de ofrecer una definición universal, ni enumerar exhaustivamente los rasgos que caracterizan el populismo. Más bien, persigo una definición de «andar por casa» y la 
enumeración de unos rasgos fundamentales que me ayuden -sin por ello faltar al rigor científico- a enfrentar con éxito la crítica de esta corriente, ideología o movimiento.

En este sentido, lo primero que habría que aclarar sería el status mismo del concepto: $i$ nos encontramos ante una verdadera ideología con el mismo rango que el comunismo, el liberalismo, etc., o, por el contrario, constituye tan sólo unos rasgos generales que pueden acompañar a las distintas ideologías?.

Si se trata del último supuesto, es decir, de un mero adjetivo que puede acompañar a distintos -e, incluso, encontrados- movimientos o ideologías, entonces sería suficiente establecer unos requisitos mínimos para poder etiquetar a cualquier movimiento o ideología como populista: que exista un líder carismático, que se haga referencia explícita y reiterada al «pueblo», etc.. Lo malo es que este ejercicio de etiquetado no sería de mucha utilidad científica y, en todo caso, seguiría dando lugar a confusiones y errores graves: ¿no da lugar a confusión, por ejemplo, meter en el mismo saco a personajes tan dispares como Reagan, Hitler y Fidel Castro?, ¿qué soluciona -o aclara- catalogar a todos ellos como populistas en base a una supuesta coincidencia de «poses» cuando si se atiende a lo fundamental, a lo verdaderamente importante- estas personas y lo que ellas representan son radicalmente distintas entre sí, diametralmente opuestas?. Y no es cierto que por los extremos lleguen a unirse; los extremos siempre son los puntos más alejados. Rouquié, refiriéndose a la especificidad del fenómeno populista en América Latina, parece llegar a parecidas conclusiones:

Si todos los partidos populares policlasistas de América Latina, de la democracia cristiana chilena a la Acción Democrática de Venezuela, pertenecen a la categoría populista, simplemente hay que concluir que ésta no tiene ninguna pertinencia (6)

$\mathrm{Si}$, por el contrario, el populismo es considerado una ideología con el mismo rango que las citadas anteriormente, entonces las características deben ser exhaustivas y dar cuenta de los aspectos esenciales, de forma que ante un acontecimiento cualquiera podamos decidir si es un fenómeno socialista, liberal o populista. En este caso, ya no podríamos poner en el mismo lado a Reagan, Hitler y Fidel aunque puedan compartir determinadas características, pero tendrían la misma importancia que podría tener el hecho de recordar que Fidel comparte con muchos otros la característica de poseer una abundante barba.

Sin embargo, si hacemos caso a Cotarelo y Paniagua, el populismo no tendría ese rango «En realidad, detrás del populismo no hay ninguna ideología, ni programa econmómico, base social o estilo político, que sea capaz de abarcarlo a todos» (7). Comparto con estos autores el criterio de no considerar el populismo como una categoría pura, pero tampoco encuentro que sea un mero conjunto de características que se pueden yuxtaponer a cualquier movimiento del signo político que sea. Voy a considerarlo, más bien, como una especie desviación o 
perversión del capitalismo -y de la ideología liberal que lo sustenta- que entra en escena en determinadas coyunturas históricas:

La interpretación que ha tenido un mayor éxito en la literatura sobre el tema es la que vincula la aparición del populismo al proceso de modernización de las sociedades en que se produce. En efecto, en casi todas éstas se percibe claramente una tensión entre los núcleos industriales, más modernizadores, y las regiones rurales más pobres y atrasadas [... ] Los movimientos populistas aparecerían así entre grupos sociales que devienen conscientes de su situación periférica respecto de los centros de poder, no sólo dentro de un mismo país, sino también en la relación entre países distintos (8).

En los autores citados aparece, pues, el populismo como fruto de una determinada coyuntura política y/o económica; pero no es fruto solamente de aquella determinada coyuntura, no es una singularidad histórica, sino que las coyunturas o crisis políticas y/o económicas constituyen el contexto más apropiado para el surgimiento $-\mathrm{y}$ resurgimiento- de este tipo de ideologías y movimientos; el mismo a través del tiempo, pero distinto en cada época histórica, lugar y circunstancias «..la forma específica que acaba cobrando el populismo depende de la clase o complejo de clases que hace suyas las interpelaciones popular-democráticas» $(9)$.

Si bien con este primer dato he aclarado algo importante -la naturaleza desviada del populismo respecto del modelo liberal-capitalista y su carácter reactivo-, aún queda referirme a los rasgos que le darían especificidad e identidad frente a otro tipo de movimientos e ideologías que se activaran en esas mismas coyunturas o crisis del sistema capitalista «En efecto, no puede negarse que los movimientos socialistas son respuestas a una crisis de modernización; que movilizan a sectores sociales que se sienten periféricos respecto de los centros de poder; que combinan elementos tradicionales con otros más modernos, etc.» (10). De entre todos destacaría cinco rasgos que -pienso- caracterizarían suficientemente al populismo.

El primer rasgo -y por sobre todos los demás- sería la apelación al pueblo. Este estaría constituido por todos los que no forman la «elite» (obreros industriales, campesinos, clase media...), es el «hombre-masa», el «hombre común». El pueblo se presenta de forma mítica; es una masa que actúa irracionalmente y que se deja llevar de la emotividad frente a una serie de objetos, bien sea el líder, la idea de nación, etc. En el pueblo se encuentran depositados los valores fundamentales de la sociedad.

El pueblo no es una clase social, sino que forma una comunidad «El populismo se opone a toda idea de conflicto social interno, e particular a la lucha de clases. El pueblo al que se refiere el populismo no es una clase sino una comunidad» (11). Pero es Laclau quien -a mi juicio- da cuenta, de forma precisa, del significado de la categoría "pueblo» en la ideología populista. Según Laclau, de la misma forma que en el nivel de las relaciones de producción existe una 
contradicción de clases, en el nivel de las relaciones políticas e ideológicas de dominación se da otra contradicción esencial que lleva al enfrentamiento pueblo/ elite o bloque de poder. Si el primero da lugar a la lucha de clases, el segundo da lugar a la lucha popular-democrática. El populismo ha sido capaz de mostrar esa contradicción, movilizando el antagonismo del pueblo frente al orden establecido. Lo que hace el populismo, en definitiva, es articular una contradicción no clasista.

El segundo rasgo que podríamos destacar, al hilo del anterior, es el sentimiento nacional. Se da en el populismo una identificación profunda entre la idea de pueblo y la de nación, al punto de resultar difícil separar populismo de «nacionalismo»:

Lo cierto es, como fuera afirmado con insistencia, que el populismo es una especie de nacionalismo cuyo rasgo básico consiste en la ecuación entre pueblo y nación [...] Está claro que el populismo, como toda ideología unitarista, que busca soldar a los individuos en torno a un proyecto común, necesita recurrir a categorías generales como la de «nación» o «patria»; todos los movimientos que se pretendían interclasistas fomentan el recurso a este tipo de objetivaciones (12).

Como afirman estos autores, el recurso a la categoría de «nación» no es exclusivo del populismo. Es un rasgo importante, pero no central como es el caso de la categoría pueblo. Mientras que el recurso a esta última categoría casi identifica, por sí sola, esta ideología, el recurso a la nación sólo no evoca necesariamente la ideología populista.

El tercer rasgo importante es la existencia de un liderazgo fuerte. Este rasgo, como el anterior, no es un elemento central del populismo. Como en el caso del recurso a la idea de nación, un liderazgo fuerte puede presentarse en otros tipos de regímenes o movimientos no necesariamente populistas. De esta opinión parece ser también Rouquié:

Cierto, no hay dudas de que el prestigio de los líderes «populistas» absolutos ante las masas urbanas ha alcanzado cumbres de popularidad y fidelidad extraordinarias [...] Sin embargo también se bautizó de populista cierto período del régimen postrevolucionario mexicano caracterizado generalmente como una «dictadura impersonal» del partido oficial [...] Si bien la personalización de un poder providencial es el elemento de semejanza más espectacular, ciertamente no es el más decisivo, ni el más central. Por lo demás, es un rasgo frecuente en América Latina, incluso en las democracias presidenciales, para no hablar del resto del mundo en desarrollo (13).

Sin embargo, hay que destacar el importante papel que históricamente ha jugado la presencia del líder en la práctica totalidad de los populismos; podríamos decir que puede haber un liderazgo no populista, pero no puede haber un populismo sin liderazgo. 
El cuarto rasgo sería la importancia del discurso populista. Sobre este tema, el artículo de Ipola ofrece un análisis interesante del discurso peronista que se pueda hacer extensivo al resto de los discursos populistas. El caso del discurso peronista es paradigmático. Junto a las características de todo discurso político (temática basada en el problema del control de las instituciones del Estado y del poder; presentación polémica; y cálculo de los efectos ideológicos y políticos inmediatos), el discurso peronista ofrece una ruptura respecto del tipo tradicional de lenguaje político:

Sin duda ello se tradujo, como lo señala Laclau, en la introducción de un nuevo principio de articulación de los elementos presentes en el espacio ideológico; pero también se tradujo en otras «novedades», a saber: a nivel de los «contenidos» en la incorporación de nuevas interpelaciones, de nuevos símbolos, de nuevos ejes de oposición, y a nivel de «formas», en nuevas técnicas de descalificación del discurso opositor y, en fin, a nuevas tácticas y estrategias para el ejercicio de la lucha ideológica (14).

Algunos de los aspectos relativos a los «contenidos»y «formas» que apunta Ipola en su artículo son: reapropiación de las interpelaciones democráticas levantadas por el discurso de la oposición; la articulación de ese «elemento» democrático a un discurso político cuyo principal eje polémico consiste en la denuncia de la «oligarquía» en nombre del «pueblo trabajador»; la progresiva incorporación de los modismos del habla popular: «Dicho de otro modo, lo que Perón busca poner de manifiesto en el adversario es, precisamente, la naturaleza enteramente 'discursiva' de su discurso, el hecho de que no sea otra cosa que mero discurso, simple fraseología» (15).

El último rasgo importante sería el papel desempeñado por el Estado en esta ideología. El Estado es la expresión del pueblo y de su historia nacional, el defensor de la identidad nacional frente a la dominación extranjera; aglutina a la comunidad nacional -recordemos que el populismo supera la división clasista y el conflicto de clases-. Tanto para Rouquié como para Touraine, el Estado es un elemento fundamental para la ideología populista. El primero llega a decir:

En este proyecto, el Estado es la institución clave, más que el presidente o el partido cuando los hay ...... La estatalización de las organizaciones socioprofesionales, la transferencia de las lealtades hacia el Estado, identificado no con un hombre, gracias a la satisfacción de demandas limitadas y sobre todo a un reconocimiento social inédito, sirven de marco a un estilo de gobierno paternalista y autoritario en el cual el clientelismo de masa burocratizado es uno de los mecanismos esenciales de un organización ficticia (16).

Esta centralidad del Estado casi nos conduciría a hablar de un tipo de populismo en acto y otro tipo de populismo en potencia: el primero sería el tipo de populismo real, el que se ha articulado históricamente en distintos países (v.gr. la Argentina peronista); el otro tipo estaría constituido por todos aquellos 
movimientos que reúnen algunas de las características anteriormente citadas (recurrencia a la categoría pueblo, a la categoría nación, presencia de un líder carismático, etc) y que ideológicamente asignan esa centralidad y ese papel al Estado.

En resumen, nos encontramos con una ideología que es, a mi juicio, un subproducto del capitalismo surgido en períodos de crisis y cuyos protagonistas son determinados segmentos de la burguesía (afectados por dicha crisis) que se alían estratégicamente con la clase obrera, formando una unidad emocional bajo la dirección de un líder carismático que provoca, en sus seguidores, un sentimiento de comunidad nacional enfrentada a la agresión exterior y a la traición interior de la oligarquía, y que se propone la conquista del Estado nacional como medio para conseguir sus objetivos.

\subsection{Pertinencia de la clase}

«Un virus patológico del movimiento obrero ....... la manifestación de un retraso ideológico y político de las masas»

Fernando Mires «Le Populisme», Les Temps Modernes, junio de 1.979.

Quizás no me atreviera a afirmar con tal rotundidad la sentencia de Mires sobre el populismo, pero sí me atrevería a decir que el populismo, en el sentido aquí expuesto, no se corresponde en absoluto con los intereses objetivos de clase de la clase obrera.

La negación de las clases -y, por supuesto, de la pertinencia de la lucha de clases- es la característica que delata más claramente la íntima familiaridad del populismo con el capitalismo. Lo que el pensamiento liberal-capitalista niega, rechaza o reinterpreta de forma erudita y elegante (17), el populismo lo hace de forma más «popular», tosca. La clase, efectivamente, se ha convertido en algo difícil no sólo de definir, sino incluso -y cada vez más- de percibir, pero, como dijera aquel gran científico, «eppur, si muove!»

Podría empezar afirmando con Wright (18) que la clase obrera sigue siendo con diferencia la más numerosa dentro de la fuerza de trabajo. El se refiere a los casos norteamericano y sueco: ¿cuánto más en Argentina o cualquier otro país de América Latina?. Pero no cabe duda que el problema de la clase no es sólo un ejercicio de constatación empírica, sino un problema teórico:

Por otro lado, el concepto de clase es un concepto «teórico», lo que quiere decir que se inscribe en el marco de una teoría de las clases sociales [...] El concepto de clase es ante todo un concepto "clasificatorio», es decir, intenta agrupar a distintos individuos a partir de un conjunto de rasgos comunes, $o$ criterios de "unificación» de clase. Una estructura de clase, por su parte, estará constituida por distintos grupos separados entre sí según criterios de «diferenciación» de clase. El primer problema, pues, que se le plantea al análisis de clase es el de hallar sendos criterios de unificación y diferenciación (19). 
Hasta aquí hemos dado, sin apenas notarlo, un paso importante en el intento de desvelar el carácter ideológico (20) del populismo. Frente a la afirmación de comunidad, todos los pensadores (marxistas, por supuesto, y no marxistas) afirman la pertinencia de la clase. Por lo tanto, existe, cuando menos, un conjunto de intereses de clase, distintos para cada clase y no un único interés del pueblo. El paso siguiente será establecer si esos conjuntos de intereses son simplemente distintos entre sí o si, además, son contrapuestos. En este último caso estaríamos afirmando también la pertinencia de la lucha de clases que es lo que, en definitiva, pretende mostrar el análisis marxista (21).

En adelante me voy a servir de los razonamientos de Erik Olin Wright para mostrar cómo, efectivamente, nos hayamos ante un conjunto de intereses no sólo distintos sino contrapuestos. Wright destaca tres tipos de efectos de la estructura de clase: ' los intereses materiales, la experiencia vivida y las capacidades para la acción colectiva. De los tres, el más determinante, a juicio del autor, es el primero. Estos intereses materiales hacen referencia a los intereses vinculados al bienestar económico y a los intereses vinculados al poder económico. Al hablar de intereses, Wright distingue entre el interés intrínseco (se refiere a los fines de la acción, a los objetivos que se pretenden conseguir mediante estrategias particulares) y el interés instrumental (intereses organizados en torno a los medios necesarios para realizar aquellos fines): «Así, por ejemplo, un nivel determinado de consumo puede entenderse como un interés intrínseco: un objetivo buscado por sí mismo; por el contrario, mejorar la propia posición de mercado para aumentar el nivel de renta es un interés instrumental» (22). De los dos, los intereses instrumentales son prioritarios. Son en estos intereses donde se observaran grandes y sistemáticas diferencias entre las clases. En cuanto a los primeros (desear un mayor nivel de vida, más tiempo para el ocio, etc...), las diferencias entre unas clases y otras son mínimas.

Aclarado este punto, paso a ocuparme de los dos conjuntos de intereses antes mencionados. En cuanto al bienestar económico hay que decir que no se refiere al ingreso o al consumo, sino al conjunto trabajo-ocio-ingreso del que dispone la persona:

los intereses de clase respecto al bienestar económico vienen determinados por lo que una persona debe hacer para conseguir un determinado nivel de bienestar económico, esto es, por los mecanismos generadores de bienestar, no por el resultado en sí. Hablar de intereses comunes de clase, pues, significa que los individuos de una clase dada, en virtud de su relación con los mecanismos subyacentes insertos en las relaciones sociales de producción, se enfrentan objetivamente a la misma estructura general de elecciones y objetivos estratégicos cuando intentan promover su bienestar económico (23).

Las relaciones sociales de producción no sólo distribuyen, mediante una serie de mecanismos, el bienestar económico, sino también el poder económico, es decir: el control sobre el plusproducto: 
la parte del producto social total que queda después de que todos los factores de producción -tanto fuerza de trabajo como capital físico-se han reproducido ...... el control capitalista privado sobre el excedente impone severos limites al ejercicio potencial del poder político democrático en una sociedad capitalista ...... lo importante aquí es que los intereses materiales están ligados a los aspectos básicos del poder social y no meramente a los del bienestar económico individual (24).

Ambos tipos de intereses materiales se conectan, en la teoría marxista, por medio del concepto de explotación: «la explotación define un conjunto de mecanismos que ayudan a explicar tanto la distribución del bienestar económico como la distribución del poder económico» (25). Así, los explotadores obtendrán más bienestar económico y más poder económico y los explotados verán recortado su bienestar económico, al apropiarse los primeros del excendente, y su poder económico al ser excluidos del control del excedente:

Dentro de la tradición marxista, los miembros de una clase no comparten simplemente algún atributo -comunes intereses materiales- sino que esos intereses están relacionalmente ligados de forma específica, a través de la explotación, a los intereses de las otras clases. Las clases relacionalmente definidas, en este sentido, no tienen simplemente diferentes intereses materiales, como para la tradición weberiana: tienen intereses materiales opuestos (26).

Aquí podría finalizar la reflexión sobre la pertinencia de la clase y de la lucha de clases. Tratar de profundizar más en este tema sobrepasa el interés del trabajo. Los diversos intentos de solución del problema de la clase media, que es la primordial preocupación de Wright en los dos libros citados son sumamente interesantes, pero nos alejaría mucho del objetivo, al tiempo que complicaría bastante el análisis de la clase.

Demostrada la existencia de clases y los intereses materiales que las enfrentan, se hace evidente, pues, la ficción populista que pretende unir en una misma bandera intereses contrapuestos en nombre de unos principios míticos y bajo el patrocinio de un líder paternalista que se encuentra más allá del bien y del mal.

No creo, en contra de lo que piensa Laclau, que, paralelamente a una contradicción clasista, exista una contradicción ideológico-política. Estoy convencido de que ésta última es, en mayor o menor grado, expresión de la primera; es decir, que existe una sola contradicción que tiene como fundamento los intereses materiales opuestos y que se manifiesta en el nivel económico, en el político y en el ideológico. Sólo estratégicamente puede darse una confluencia de intereses en el nivel ideológico-político, pero ésta desaparecerá tan pronto como la clase económicamente dominante, que se ha unido coyunturalmente a la clase obrera, haya conseguido sus objetivos. Además, desde el punto de vista teórico, no parece correcto pensar que pueda existir simultáneamente una contradicción inherente a las relaciones de producción que explicaría la lucha 
de clases, y una contradicción inherente a una formación social concreta que explicaría la lucha popular-democrática. Estaríamos -si no entiendo mal la propuesta de Laclau- ante la posibilidad de ver a clases enfrentadas en una lucha de clases, unidas en una lucha popular-democrática contra un enemigo común.

En todo caso, el juicio negativo sobre el populismo he pretendido que no sea moral como denuncia Rouquié (27) o, al menos, no solamente moral.

\section{ARGENTINA Y EL PERONISMO}

En esta segunda parte del trabajo me voy a centrar en la Argentina de Perón por constituir, a mi juicio, un caso prototípico de régimen populista en América Latina. Trataré de profundizar en las causas que provocaron su surgimiento en este país, las formas peculiares que adquirió (modos, discursos, etc.) y sus logros durante los años en que Argentina fue gobernada por su líder, Juan Domingo Perón.

\subsection{El contexto}

Touraine, encuentra en la reacción nacionalista de los latinoamericanos frente a los procesos de modernización dirigidos desde el exterior, la causa que explica el surgimiento de los distintos populismos en esta parte del continente, por encima de las singularidades propias de cada país:

En los países donde la modernización es, en gran parte, importada nace el deseo de un desarrollo que sería lo contrario de una modernización dependiente y que preservaria, o incluso restablecería, los aspectos fundamentales de la identidad nacional. El populismo es esa reacción, de tipo nacional, a una modernización que está dirigida desde el exterior (28).

La constatación de estos hechos (tanto el de la naturaleza dependiente como el de la reacción xenófoba provocada por esta circunstancia) le va a permitir definir un modelo político típico para América Latina: lo que él llama la política nacional-popular. A partir de este concepto, irá analizando tanto los partidos de tendencia populista en los distintos países (Gaitán y López en Colombia, el APRA peruano, MNR boliviano, el PRI mexicano, etc.), como los Estados nacional-p opulares propiamente dichos, cuyo ejemplo más conocido es Argentina, pero también el Chile de Eduardo Frei (1964-1970), Ecuador bajo la presidencia de Roldós y O. Hurtado, el gobierno de Acción Democrática en Venezuela (sobre todo en el trienio 1948-1950), la Guatemala de Arévalo y Arbenz, Jamaica con Manley, etc..

Con ésto, ya hemos dado un paso en la contextualización del fenómeno populista en Argentina: éste no es un caso aislado, una especie de azar, sino que se enmarca en un contexto mucho más amplio y responde, en su forma general, a un entramado de elementos estructurales del sistema (la relación de dependencia 
Norte/Sur es la versión internacional de la relación de explotación en el sistema de producción capitalista) y otros coyunturales (29) (crisis económicas y políticas, surgimiento de líderes carismáticos, etc.).

No obstante, no hay acuerdo en este punto. Rouquié, por ejemplo, circunscribe el fenómeno populista a un par de décadas y, además, critica el generoso uso que se hace del concepto populista al aplicárselo a muy distintas experiencias políticas. De todas formas, a los efectos de este trabajo no importa demasiado si el período se extiende más o menos en el tiempo, ni siquiera si la amplitud del concepto es la adecuada o no. Ninguno de los autores rechaza la etiqueta «populista» para el movimiento peronista y ambos reconocen, con más o menos reservas, que el fenómeno se extiende más allá de las fronteras argentinas, alcanzando al conjunto de América Latina con más o menos intensidad. Incluso en las causas que subyacen en el fenómeno parecen coincidir en buena medida, pues si Touraine habla de modernización dependiente, Rouquié habla de crisis de los sistemas agroexportadores, es decir, en ambos casos el elemento «exterion» juega un papel importante. Calvocoressi también destaca la dependencia de la ayuda extranjera como causa del creciente sentimiento xenófobo en Latinoamérica (30).

Pero no es sólo común a Latinoamérica el hecho de la dependencia exterior, también la herencia colonial lastra la historia de estos países poderosamente; la debilidad -0 , simplemente, la ausencia- de una clase media, igualmente, ha conducido a un profunda dualización social: por un lado, la oligarquía en modo alguno preocupada por la modernización e industrialización de sus países y a las que les bastaba con exportar los productos de la tierra con cuyos beneficios podía adquirir los artículos de importación «..del mismo modo que el desarrollo industrial se había visto frenado por la autosuficiencia de una clase dirigente capaz de mantener su nivel de vida exportando productos primarios y utilizando los ingresos para importar todas las necesidades y lujos que»quería del mundo exterior» (31) y, por el otro, las masas «cuya miseria e ignorancia las convertía no tanto en ciudadanos conscientes del juego político como en instrumentos fáciles de manipular» (32). Esto hacía difícil la implantación del sistema representativo que había triunfado en Europa y EE.UU. y que se intentó importar a Latinoamérica. Este sistema se basa en un consenso que supone un equilibrio entre las distintas fuerzas sociales y la aceptación de las minorías de las decisiones de las mayorías, algo prácticamente inviable en el contexto latinoamericano.

Por tanto, podemos concluir que la política nacional-populista, al decir de Touraine, es una experiencia más o menos común en América Latina; experiencia que se ve facilitada por la propia situación interna de la región (la descrita más arriba: lastre colonizador, dualización y polarización social, ausencia de procesos de industrialización, cultura política proclive al autoritarismo, histórica presencia de la figura del caudillo, etc.) y por la relación de subordinación exterior que provoca sentimientos nacionalistas y xenófobos en buena parte de la población latinoamericana. Ambas situaciones (interna y externa) en conjunción con determinadas coyunturas históricas (crisis del 29, fortalecimiento de la clase 
media, etc) y la aparición de líderes carismáticos, serían los ingredientes básicos que provocarían su aparición.

\subsection{El país}

Conviene ahora hacer un breve repaso de la situación política, social y económica del país en el período previo a la subida al poder de Perón. Esto ayudará a entender más cabalmente el surgimiento del populismo argentino y la erección como líder indiscutido de este movimiento del coronel Juan Domingo Perón.

La base económica de Argentina, durante mucho tiempo estuvo constituida por la exportación de productos derivados del ganado vacuno, al que se sumó más tarde el de ganado ovino debido a la fuerte demanda europea de lana. Junto al sector ganadero-exportador, también experimentó, desde mediados del siglo XIX, un fuerte desarrollo el sector agrícola. Esto produjo un extraordinario flujo de inmigrantes, sobre todo europeos (33) que, a su vez, provocó un rápido y constante crecimiento urbano en el país (la urbanización pasó del $29 \%$ en 1870 al 53\% en 1914). Las modificaciones en la infraestructura realizada por la inversión británica, estimularon el impulso agroexportador. De igual modo, la instalación de frigoríficos en los años ochenta fueron un factor dinámico de las transformaciones. Este período, 1880-1914, es un período de gran expansión para las inversiones extranjeras, especialmente británicas. El sector financiero fue pronto dominado por la banca inglesa (34).

Pero la oligarquía argentina, que era consciente de la aparición de otros intereses económicos y políticos representados por las nacientes clase obrera urbana y clases medias que habían surgido al socaire del crecimiento económico, seguía dispuesta a no hacer concesiones en su monopolio de poder. Esto va a dar lugar a varios intentos revolucionarios como el de 1890, el de 1893 protagonizado por la Unión Cívico Radical de Hipólito Yrigoyen o el de 1905 protagonizado también por Yrigoyen. Pero no sólo se produjeron estos intentos revolucionarios, en las áreas rurales también se produjeron estallidos diversos y el proletariado industrial, en crecimiento, protagonizó huelgas importantes.

El estallido de 1905, a pesar de su fracaso, hizo que el radicalismo ganara prestigio entre los opositores al régimen oligárquico. Yrigoyen ganó, así, las elecciones de 1916 gracias al voto popular. La ambigüedad de su programa permitió, además, aglutinar a su alrededor a sectores muy diversos. Su intento de reducir el predominio británico en la infraestructura económica tuvo, sin embargo, muy escaso éxito, pero marcó el camino para la recuperación de sectores nacionales en poder de empresas extranjeras. Por otro lado, su política obrera se redujo prácticamente a un llamado a la conciliación de las clases.

A Yrigoyen le sucedió Marcelo Torcuato de Alvear para retornar al poder en 1928 , pero el panorama político no era ya muy favorable a su persona: la 
UCR se dividió y la oligarquía estaba decidida a erosionar el gobierno. La escisión entre Yrigoyen y las clases altas se hizo definitiva:

La crisis que se inició en 1929 y las normas que las potencias europeas y EE.UU. aplicaron en los años siguientes anarquizaron ese sistema económico internacional en vigencia desde hacía más de sesenta años. Desapareció en gran parte el comercio multilateral, reemplazado por el tratado bilateral y por innumerables restricciones, manejadas muchas de ellas como salidas de emergencia. La demanda de productos primarios se redujo considerablemente en el mercado internacional. El Reino Unido introdujo en 1932 el sistema de preferencia imperial con los pactos de Ottawa y colocó a sus proveedores de materias primas, Argentina entre ellos, en la necesidad de aceptar pactos bilaterales que incluían compromisos onerosos en muchos rubros (35)

El descontento social hacía necesario un férreo control político que salvase del desastre a la oligarquía agro-exportadora e impidiera el acceso al poder a otros grupos emergentes. De este modo, el 6 se setiembre 1930, se sublevó el general José Félix Uriburu y depuso al vicepresidente que sustituía al enfermo y anciano presidente, rompiéndose la normalidad constitucional vigente desde 1861. Uriburu, después de un período autoritario, volvió a la normalidad democrática poniendo el gobierno en manos conservadoras. Así, se celebraron elecciones el 8 de noviembre de 1931 en la que se abstuvieron los radicales y de la que salió vencedor el general Agustín Pedro Justo. Se abordó rápidamente la cuestión esencial de los conservadores: el comercio con Inglaterra. Se envió una delegación de alto nivel a Londres y se firmó el Tratado Roca-Runciman. Para algunos es la etapa de más completo sometimiento colonial de Argentina a los intereses británicos («década infame»).

Las medidas oficiales sostenían los intereses de las clases dominantes, pero no podían evitar que surgieran otras fuerzas económicas que pretendieran defender políticamente sus intereses. Comenzaba a florecer una industrialización fruto de la sustitución de importaciones. En las elecciones de 1937 un nuevo conservador asumió el poder, Roberto M. Ortíz. Con el estallido de la segunda guerra mundial se produjo una escisión entre los partidarios de romper las relaciones con las potencias del Eje y un sector nacionalista que defendía la idea de la neutralidad, sobre todo los militares (36). Al morir Ortíz, asume la presidencia Ramón S. Castillo quien optó por el mantenimiento de la neutralidad.

En 1943 se produjo un nuevo golpe militar que intentó acabar con el inestable equilibrio, pretendía evitar el riesgo de una decisión en contra de la neutralidad por parte de los partidos políticos. Asumió el cargo de presidente el general Pedro Pablo Ramírez. Este sufrió intensas presiones para romper la neutralidad hasta que el 26 de febrero de 1944 rompió relaciones Alemania y Japón. Pocos días después, el 9 de marzo de 1944, fue destituido por esta razón y asumió la presidencia el general Farrell que, a su vez, se vió obligado a declarar la guerra a Alemania el 27 de marzo de 1945. 
El gobierno militar desarrolló una política económica nacionalista y de apoyo al sector industrial, por un lado; y una política social y una legislación laboral abiertamente progresiva, por otro (hay que recordar que Perón fue uno de los organizadores del golpe militar de 1943 y, además, formó parte de ese gobierno). Sin embargo, el gobierno va a ser contestado por los sectores económicos tradicionales, los partidos políticos, la prensa, etc. que se agruparán en la Unión Democrática. Cuando todo parecía indicar que Farrell se disponía a traspasar las funciones a la Corte Suprema de Justicia para iniciar un nuevo proceso electoral democrático, irrumpió en la escena el proletariado argentino aglutinado en torno a la figura de Perón.

\subsection{El movimiento}

1) La verdadera democracia es aquélla donde el gobierno hace lo que el pueblo quiere y defiende un solo interés: el del pueblo.

2) El peronismo es esencialmente popular. Todo círculo político es antipopular, y por lo tanto no es peronista.

3) El peronista trabaja para el Movimiento. El que en su nombre sirva a un círculo o a un caudillo, lo es sólo de nombre.

4) No existe para el peronismo más que una sola clase de hombres: los que trabajan.

5) En la Nueva Argentina el trabajo es un derecho que crea la dignidad del hombre, y es un deber, porque es justo que cada uno produzca por lo menos lo que consume.

6) Para un peronista no puede haber nada mejor que otro peronista.

7) Ningún peronista debe sentirse más de lo que es ni menos de lo que debe ser. Cuando un peronista comienza a sentirse más de lo que es, empieza a convertirse en oligarca.

8) En la acción política la escala de valores de todo peronista es la siguiente: primero la Patria, después el Movimiento y luego los hombres.

9) La política no es para nosotros un fin, sino sólo el medio para el bien de la Patria, que es la felicidad de sus hijos y la grandeza nacional.

10) Los dos brazos del peronismo son la justicia social y la ayuda social. Con ellos damos al Pueblo un abrazo de justicia y amor.

11) El peronismo anhela la unidad nacional y no la lucha. Desea héroes, pero no mártires. 
12) En la Nueva Argentina los únicos privilegiados son los niños.

13) Un gobierno sin doctrina es un cuerpo sin alma. Por eso el peronismo tiene su propia doctrina política, económica y social: el Justicialismo.

14) El Justicialismo es una nueva filosofía de la vida, simple, práctica, popular, profundamente cristiana y profundamente humanista.

15) Como doctrina política, el Justicialismo realiza el equilibrio del derecho del individuo con el de la comunidad.

16) Como doctrina económica, el Justicialismo realiza la economía social, poniendo el capital al servicio de la economía y ésta al servicio del bienestar social.

17) Como doctrina social, el Justicialismo realiza la justicia social, que da a cada persona su derecho en función social.

18) Queremos una Argentina socialmente justa, económicamente libre y políticamente soberana.

19) Constituimos un gobiemo centralizado, un Estado organizado y un Pueblo libre.

20) En esta tierra lo mejor que tenemos es el pueblo.

«Las veinte verdades», formuladas por el jefe del Justicialismo, Juan D. Perón, en 1.950 .

Intentar una caracterización del peronismo, como del populismo en general, no es tarea fácil dada la riqueza de matices observables en este movimiento y la variedad de temas que nos pueden servir de referencia para efectuar nuestro análisis: ¿analizamos el justicialismo a partir de lo que él dice de sí mismo?, ¿desde las múltiples críticas que se han hecho sobre él?, ¿lo hacemos partiendo de sus realizaciones históricas?, ¿en una perspectiva comparada? (37), etc.. Por mi parte -y dadas las características del presente trabajo- voy a enfrentar la tarea de caracterizar el peronismo desde una doble reducción: una primera temporal: me voy a limitar a los dos primeros gobiernos de Perón (éste será el contenido del siguiente apartado de este trabajo); una segunda intelectual: me voy a servir fundamentalmente del análisis del peronismo realizado por Gino Germani porque de los autores que he podido consultar es el que, a mi juicio -y a pesar de las oportunas observaciones de Tulio Halperin Donghi, Eldon Kenworthy, Louise Doyon, etc.-, presenta un cuadro más completo y coherente de este fenómeno.

Indudablemente el contraste con el fascismo europeo es una cita obligada en el análisis del peronismo (hay que recordar, no más, que Perón fue agregado militar en Italia a comienzos de la $2^{\mathrm{a}}$ Guerra Mundial lo cual, sin duda, influiría en su posterior etapa como jefe indiscutido del movimiento que lleva su nombre). 
El contraste entre el régimen peronista y el fascismo-nazismo se debe a que ambos tipos de regímenes tienen elementos comunes, pero -y quizás más importante- a que existen otros muchos elementos que los distinguen. La primera gran diferencia que surge de esta comparación es que la base humana de uno y otro movimiento es distinta. Mientras que en el fascismo (en adelante emplearé el término «fascismo» por comodidad para referirme al fascismo y al nazismo indistintamente) la base social esta compuesta por la burguesía y la clase media inferior, con una participación muy reducida del proletariado, el peronismo se basó esencialmente sobre el apoyo de grandes sectores de las clases trabajadoras urbanas y rurales (38).

Entre las causas que explicarían el apoyo de esos sectores populares al peronismo, se podrían apuntar el rápido proceso de industrialización y urbanización masiva que produjo una clase popular masificada de formación reciente que no tenía apenas experiencia sindical, ni había tenido tiempo de ser politizada por los partidos tradicionalmente obreros; además, debido al carácter inmigratorio de la población y otros factores históricos, la clase media también era reciente y no tenía las tradiciones de prestigio, etc. de la vieja clase media europea; no había un problema específico de proletarización de las clases medias, más bien ésta había sido fruto de un ascenso social reciente; pero sí existía un problema de integración de las clases populares por sus condiciones de vida (sobre todo en la zona del Gran Buenos Aires) y trabajo.

Esto no niega los elementos psicosociales comunes a ambos tipos de movimientos: la identificación de la masa con el líder, el contacto directo, personal, es un poderoso vehículo en la formación de la pseudoparticipación necesaria para el consentimiento en ambos tipos de regímenes. Sin embargo, hay que señalar que el fascismo no logró, a diferencia del peronismo, el apoyo activo de la mayoría de los trabajadores urbanos y rurales. Hubo más bien aceptación pasiva. Por otro lado, mientras que el fascismo hablaba de la «colaboración de las clases», el peronismo hablaba de las tensiones entre las clases, del enfrentamiento entre las clases trabajadoras y la «oligarquía explotadora», aunque en realidad nunca pretendió alterar la estructura social del país.

El apoyo de las clases populares al peronismo, según la versión generalizada, se debió a la demagogia de la dictadura. Pero, a juicio de Germani, esta razón es insuficiente porque esa versión interpreta que el pueblo vendió su libertad por «un plato de lentejas». Para Germani:

la parte efectiva de esa demagogia no fueron las ventajas materiales, sino más bien el haber proporcionado al pueblo la experiencia (ficticia o real) de que había logrado ciertos derechos y que los estaba ejerciendo. Los trabajadores que apoyaban la dictadura, lejos de sentirse despojados de la libertad, estaban 
convencidos de que la habían conquistado [...] su actitud no era, como muchos pretenden, de agradecimiento al dictador por las «dádivas» (aunque, por supuesto, esta clase de sentimiento no faltó en muchos), sino de orgullo por haber logrado (impuesto sería la palabra psicológicamente más exacta) sus derechos frente a la clase patronal» (39).

Para Gabriela de la Mata tampoco es una cuestión de dávidas; el peronismo supuso, según esta autora, la institucionalización de los derechos sociales:

«Puede decirse que en el caso de Argentina, los derechos sociales han constituido históricamente la categoría prevaleciente: claramente hegemónicos para los sectores que se constituyen políticamente por medio del peronismo [...] Es que el Estado, a partir del peronismo, había institucionalizado los derechos sociales como fórmula de inclusión política de los sectores excluidos, generando más allá del reconocimiento político de estos actores respecto del líder y del sistema, su reconocimiento como portadores de esos derechos. En definitiva, estos actores construyeron su identidad política en la adquisición de ciudadanía social(40).

No cabe duda que el peronismo guarda sus distancias con las experiencias fascistas, pero, en último término, esas diferencias son debidas más al propio contexto histórico de esos países (a sus diferencias económicas, sociales, culturales, políticas, incluso a su distinto momento dentro de la evolución políticoeconómica del capitalismo) que, digamos, a la filosofía que subyace en este tipo de movimientos. En este sentido, la semejanza entre fascismo y peronismo es bastante más amplia que la sola coincidencia psicosocial de la identidad masalíder; y si atendemos a los «resultados finales» de la gestión política de estas ideologías (escasos resultados económicos, corrupción política, personalismo, persecución policial, encarcelamiento, represión etc.) en vez de a su filosofía, sus semejanzas aún pueden llegar a ser mayores.

\subsection{EI hombre}

Juan Domingo Perón nació en 1895 en Lobos, pequeño pueblo de la provincia de Buenos Aires. En 1911 ingresó en el Colegio Militar Argentino. En 1915 fue ascendido a teniente y destacó en algunas actividades deportivas (boxeo, esgrima, esquí). En 1925 alcanza el grado de capitán y un año más tarde ingresó en la Escuela Superior de Guerra donde obtuvo el diploma de Estado Mayor. En 1929 contrajo matrimonio con una maestra de guitarra que murió pocos años después, en 1938. Militar intelectualizado, fue profesor de la Escuela Superior de Guerra y escribió algunos libros de historia militar. Tenía un carácter simpático y poseía un notable «don de gente». Hasta obtener el grado de coronel, en 1941, su carrera militar no hacía presagiar nada excepcional en el plano político. Fue agregado militar de la Embajada argentina en Chile y en Italia al comienzo de la segunda guerra mundial, además viajó en misión especial por España, Francia, Alemania y la URSS. Fue, también, un destacado miembro del GOU (Grupo de Oficiales Unidos que protagonizó el golpe militar de 1943). Él mismo participó 
activamente en el golpe y, tras éste, Farrell le nombró jefe de la secretaría de su ministerio, puesto clave para conocer los entresijos del poder.

Perón intervino en la solución de un conflicto laboral muy importante, surgido en la industria de frigoríficos, negociando con éxito un arreglo con los líderes sindicales. Descubrió, de este modo, su potencial como líder y la fuerza potencial de los trabajadores y sus sindicatos, y se propuso «identificarse» con ellos. Reclamó para sí la dirección de la política laboral del régimen: el puesto de Jefe del Departamento Nacional de Trabajo. Desde este puesto trató de ganarse a los trabajadores con medidas sociales, obteniendo éxito en este empeño: Perón se reunía con los trabajadores, hablaba su lenguaje, plasmaba en medidas legales concretas sus reivindicaciones. De esta forma extendió su influencia política al tiempo que se creó una plataforma al margen de los partidos clásicos, gracias al apoyo de los sindicatos (41).

Perón luchó, además, por la cartera de Guerra y lo consiguió; sin tener que abandonar los dos cargos que ostentaba, el 7 de Julio de 1944 ocupó la vicepresidencia. Su poder asustó tanto que las íras de la oposición (oligarquía tradicional, empresariado, socialistas, comunistas, etc.) se dirigieron contra él, hasta el punto que una parte del ejército llevó a cabo un golpe de Estado con la intención de desalojar del poder a Perón más que contra el presidente Farrell. Perón fue destituido y se retiró con Eva Duarte a casa de un amigo. Pero, más tarde, se le detuvo y se le confinó en la isla Martín García. Se convocó una huelga general para el día 18 que se adelantó al 17 para exigir la presencia del líder. El presidente recibió a los dirigentes sindicales de la Confederación General del Trabajo quienes le exigieron la no entrega del poder a la Corte Suprema de Justicia, la formación de un gobierno amplio que consultase a las organizaciones sindicales, la convocatoria de elecciones libres, el levantamiento del estado de sitio, el mantenimiento de las conquistas sociales y, por supuesto, la libertad y presencia de Perón. Farrell accedió a las peticiones y el 4 de noviembre se convocaron elecciones generales y presidenciales el 24 de febrero de 1946.

A esas elecciones se presentó, por un lado, Perón que contaba con el apoyo de un pequeño partido laborista creado por los líderes sindicales, un sector radical yrigoyenista (Junta Renovadora), algunos grupos nacionalistas como la Alianza, el diario «La Epoca», etc.; por otro, la Unión Democrática. El 24 de febrero dio el triunfo a Perón quien, apoyado en los sindicatos y en los sectores nacionalistas de las Fuerzas Armadas, inició su gobierno. Como instrumento político, integró las distintas fuerzas que le habían apoyado en el Partido Unico de la Revolución (24 de noviembre de 1946) que se llamó luego Partido Peronista (15 de marzo de 1947). Más tarde surgiría el Partido Peronista Femenino bajo la dirección de Evita.

El programa peronista -o justicialista- se resume en el lema «por una nación socialmente justa, económicamente libre y políticamente soberana». La legislación laboral se desarrolló vigorosamente; también se puso en práctica una política de nacionalizaciones (Banco Central, ferrocarriles, gas, etc.); se puso en marcha, además, una serie de planes quinquenales con el objeto de 
fomentar el desarrollo industrial, etc.. Perón modificó la Constitución de 1853 para permitir su reelección como presidente de manera consecutiva («Constitución Justicialista»).

Pero pasada la etapa del comercio exterior favorable a Argentina, la alianza de clases que esa época feliz había promovido, comenzó a resquebrajarse. Ya los intereses de obreros y capitalistas se hacían cada vez más difíciles de conciliar. En las elecciones presidenciales del 51 pudieron votar, por primera vez, las mujeres. En éstas se presentó, por un lado, Perón y, por otro, la oposición dividida en cuatro partidos (radicales, demócratas, socialistas y comunistas). La victoria de Perón fue abrumadora ( $62,49 \%$ de los votos). Así, inició su segundo mandato el 4 de junio de 1952. Pero las nuevas circunstancias económicas llevaron al presidente a virar hacia posiciones más moderadas y conservadoras aunque siguió presentando un discurso radical y obrero. A estas circunstancias adversas se sumó la muerte de Evita, pieza esencial de su política por la simpatía que el pueblo sentía por ella (42). Se puso en marcha el segundo plan quinquenal: se volvió a prestar atención a la agricultura y la política de nacionalizaciones fue sustituida por el aliento a la inversión extranjera.

En su aspecto político, el régimen iba asumiendo un aire cerrado, crecientemente antidemocrático (cierre de locales de la oposición, detenciones arbitrarias, vigilancia, intervenciones telefónicas, etc.). El régimen se volcó hacia el culto a la personalidad del líder. Va, así, perdiendo adhesiones, al mismo tiempo que comenzó un proceso de descrédito del régimen. En este clima, se produjo en Buenos Aires, el 16 de junio de 1955, una sublevación antiperonista que fracasó, pero dejó muchos muertos. El golpe lo protagonizó la Marina, pero el ejército de Tierra le permaneció fiel; no obstante, el control de la situación asumida por el ejército impuso a Perón un giro político: frente a la idea de represalia, le impuso la idea de pacificación, de retono a la vida democrática, con libertades para la oposición y el fin de la campaña contra la Iglesia católica que había servido como estrategia al Presidente para distraer la atención de la población.

Perón pareció aceptar y someterse al nuevo papel, pero la convivencia no prosperó y decidió recuperar el pleno poder mediante la estrategia de renunciar para volver con más fuerza. El 31 de agosto anunció el abandono de la presidencia, su gente se encargó de agitar a las masas que se concentraron en la Plaza de Mayo nuevamente y Perón, ante el fervor de las masas, decidió renunciar a renunciar. Pero el 16 de setiembre, un nuevo levantamiento, de mayores dimensiones y con el apoyo de casi todo el ejército, acabó con su mandato. Perón dimitió el 18 de setiembre y marchó al exilio.

Con la marcha de Perón al exilio se podría dar por finalizado este trabajo, que no el peronismo. Perón y el peronismo continuó -continúa- pujante durante mucho tiempo en la clandestinidad, en la oposición y nuevamente en el poder. Podría ser motivo de un trabajo interesante el estudio en profundidad del peronismo de las catacumbas porque no cabe duda que este personaje y su 
movimiento, al margen de críticas o alabanzas, han ejercido una poderosa influencia en el pueblo argentino durante décadas y más allá del período de gobierno.

El reconocimiento de esta influencia, incluso el reconocimiento de la parte positiva de la gestión de Perón y del justicialismo, en general, no invalida en absoluto la crítica (que he pretendido seria) vertida en este trabajo sobre el populismo, del que el peronismo es buque insignia en América Latina.

\section{CONCLUSIONES}

Brevemente voy a señalar algunas de las conclusiones de este trabajo. La primera de ellas sería la de que el populismo no es la tercera vía como pretendía Perón y sus seguidores, sino que es, básicamente, una forma local de la ideología liberal-capitalista -con mucho ropaje-, que surge en determinadas coyunturas históricas.

La segunda conclusión importante es que, si bien el populismo no se desmarca en absoluto del modelo capitalista, sí es diferente de cierto tipo de totalitarismo con el que tradicionalmente se le ha querido identificar -el fascismo-, pero, del mismo modo, está muy lejos de identificarse con un movimiento revolucionario. El populismo tiene la suficiente entidad como para, sin llegar a constituir una tercera vía, no ser un mero adjetivo que se pone al lado de cualquier tipo de movimiento o personaje sea éste reaccionario o, sobre todo, revolucionario.

La tercera conclusión tiene que ver con el carácter mistificador de este movimiento, sobre todo lo referido a las clases. Aquí he tratado de mostrar, más mal que bien, la existencia objetiva de las clases sociales y su carácter contradictorio en cuanto que enfrentan intereses no sólo distintos sino contrapuestos. Esta és una realidad objetiva, independientemente de que se la quiera ignorar, tergiversar, etc., e independientemente de que, en determinadas coyunturas históricas, pueda darse una colaboración entre la clase trabajadora y una parte de la clase capitalista.

La cuarta, y última conclusión, sería la de que el peronismo es un ejemplo paradigmático de populismo porque muestra con claridad los rasgos fundamentales que hemos descrito a lo largo de estas páginas: su recurrencia a la categoría «pueblo» y a la de «nación», el carácter carismático de su líder, las cualidades populistas de su discurso, así como la importancia del papel jugado por el Estado peronista.

\section{NOTAS.}

(1) Emilio de Ipola, en su estudio sobre el populismo en la obra de E. Laclau ( Populismo e ideología: a propósito de E. Laclau», Ipola de, Emilio. «En 
teoría», núm. 4, Enero-Marzo 1.980) comenta cómo éste comprueba la aplicación del calificativo «populista» a fenómenos históricos distintos: el narodnichestvo del siglo XIX en Rusia, los fascismos alemán e italiano, el peronismo y el varguismo en América Latina, el nasserismo, el poujadismo francés y hasta el PC italiano.

(2) Ramón García Cotarelo y Juan Luís Paniagua recogen en su libro «Introducción a la Ciencia Política», en forma esquemática, la tipología de movimientos a los que se aplica el término populista según M. Canovan. Se atribuye carácter populista al radicalismo agrícola o rural del que es un típico ejemplo el movimiento populista norteamericano, al populismo intelectual revolucionario (Fanon, Nyerere), al populismo campesino (unión nacional agraria búlgara), dictaduras populares (J. D. Perón), a las democracias populistas (movimiento progresista norteamericano), al populismo reaccionario (George Wallace), al populismo de los políticos (De Gaulle, Reagan).

(3) Ibid., pág. 432-433. Rouquié opina algo parecido: «El término remite pues a realidades muy heterogénas y sin puntos comunes» (Rouquié, Alain, «América Latina. Introducción al extremo occidente», Siglo XXI, México, 1.989, pág. 279).

(4) Boron, Atilio A., «Estado, Capitalismo y Democracia en América Latina», Ediciones Imago Mundo, Buenos Aires, 1.991, pág. 13.

(5) Ipola afirma que es una presuposición falsa pensar que cuanto más pobre (en el sentido de más acotado, según entiendo) sea el concepto, mayor es su capacidad explicativa. Si bien esto puede ser cierto, no quiere decir que lo contrario (una difusa delimitación) implique, en realidad. mayor poder explicativo. Tanto un extremo como otro pueden conducir a un empobrecimiento en la explicación del fenómeno; uno por exceso y otro por defecto. No se trata de cerrar rígidamente el concepto, pero tampoco de «dejar el campo sin 'vallao'».

(6) Rouquié, Alain, pág. 281, op. cit..

(7) García Cotarelo, Ramón y Juan Luís Paniagua Soto, pág. 433, op. cit..

(8) Ibid., pág 435.

(9) Ibid., pág. 436.

(10) Ibid., pág. 435.

(11) Touraine, Alain, «América Latina. Política y sociedad», Espasa, Madrid, 1.989 , pág. 167.

(12) García Cotarelo, Ramón y Juan Luís Paniagua Soto, pág 438-439, op. cit.. 
(13) Rouquié, Alain, pág. 279-284, op. cit.

(14) Ipola de, Emilio, pág. 149, op. cit..

(15) Ibid., pág. 152.

(16) Rouquié, Alain, págs. 284-285, op. cit.

(17) Por ejemplo, Crompton, glosando la definición de clase social de Weber, dice: «Así, la 'situación de clase' refleja 'oportunidades de vida' determinadas por el mercado. Los componentes causales que contribuyen a estas oportunidades de vida incluyen la propiedad, que determina la diferencia entre las clases positiva o negativamente privilegiadas (es decir, los propietarios y los no propietarios), y las cualificaciones y la educación, que dan lugar a las clases 'comerciales' o 'adquisitivas' positiva o negativamente privilegiadas»; más adelante se refiere a T.H. Marshall, «su tesis principal es que las igualdades básicas que comparten todos los «ciudadanos» de las democracias industrializadas occidentales contemporáneas sirven tanto para reducir como para legitimar las desigualdades persistentes entre las clases sociales (capitalistas). En una frase suya muy citada afirmó: 'en el siglo XX, la ciudadanía y el sistema de clases capitalista han estado enfrentados'» («Clases y estratificación», Rosemary Crompton, Tecnos, pág. 50). Giddens también comenta a otros autores que han escrito sobre las clases como, por ejemplo, Dahrendorf: "Con arreglo al esquema conceptual de Dahrendorf se deduce que la sociedad 'post-capitalista' es necesariamente una sociedad clasista. Pero, no menos evidentemente, su sistema de clases es muy diferente del que es propio del capitalismo. El más significativo de los diversos cambios mediante los que Dahrendorf trata de distinguir el 'capitalismo' del 'post-capitalismo' es la separación institucional de los conflictos industrial y político» ( $\ll$ La estructura de clases en las sociedades avanzadas», Anthony Giddens, Alianza Universidad, pág. 64). Las citas anteriores son suficientes para mostrar la preocupación de grandes pensadores por dar explicaciones alternativas a la explicación marxista de la existencia de las clases sociales; explicaciones que, a mi juicio, no pueden ocultar la intuición esencial del Marx y de otros pensadores, llamémosles, de «izquierdas»: la existencia de pobres y ricos (personas y/o naciones) no se debe a la voluntad divina, sino que es fruto de un determinado juego de relaciones económicas en el que el bienestar de unos pocos está en relación inversamente proporcional al malestar de muchos. El que técnicamente la teoría marxista tenga crasos errores o hayan cambiado determinadas disfuncionalidades en el sistema capitalista con el paso del tiempo, no invalida en absoluto, a mi juicio, esa intuición primordial.

(18) Wright, Erik Olin, «Clases», Siglo XXI, Madrid, 1.994, pág 313.

(19) Francisco de, Andrés, «Problemas del análisis de clase: a modo de introducción», en «Teorías contemporáneas de las clases sociales», Julio Carabaña et alii, Ed. Pablo Iglesias, 1.994, pág. 2. 
(20) Ideología en el sentido apuntado por Karl Manheim, es decir, como disfraz que oculta tras su ropaje su verdadera intencionalidad, su propio interés, no en el sentido de cosmovisión: «El concepto particular de 'Ideología' implica que el término expresa nuestra escepticismo respecto de las ideas y representaciones de nuestro adversario. Se considera a éstas como disfraces más o menos conscientes de la verdadera naturaleza de una situación, pues no podría reconocerla sin perjudicar sus intereses. Tales deformaciones abarcan todo el camino que media entre las mentiras conscientes, las semiconscientes y las involuntarias disimulaciones; entre los intentos deliberados para engañar al prójimo y el engaño de uno mismo» («Ideología y utopía», Karl Manheim, Fondo de Cultura Económica, México, 1.993, pág. 49).

(21) Wright, Erik Olin, «Reflexionando, una vez más, sobre el concepto de estructura de clase», en Julio Carabaña et alii, pág. 17, op. cit..

(22) Ibid., pág. 33.

(23) Ibid., pág. 34.

(24) Ibid., págs. 35-36.

(25) Ibid., pág. 37.

(26) Ibid., pág. 39.

(27) Rouquié, Alain, pág. 279, op. cit:: «Así la mayoría de las definiciones muy poco satisfactorias del populismo son resultado de una concepción moral y hasta moralista; liberales o marxistas, consideran este fenómeno como una aberración censurable».

(28) Touraine, Alain, pág 165, op. cit..

(29) En cuanto a los elementos coyunturales habría que hacer mención a uno muy importante que apunta Gino Germani como es el «clima ideológico» del período: «Hay una tercera circunstancia que ocupa un lugar esencial en este intento de explicación de ciertos aspectos del autoritarismo en las clases populares. Nos referimos al cambio de «clima ideológico» entre el siglo XIX y el siglo XX. Durante el período de ascensión de las formas democráticas ... el clima ideológico podría definirse como prevalentemente democrático. Pero, desde la segunda década del siglo actual y, más precisamente, desde la primera guerra mundial y el terrible desencadenamiento producido tras aquella contienda, las ideologías dominantes durante el periodo anterior sufrieron un fuerte desgaste» («Política y sociedad en una epoca en transición», Gino Germani, Paidós, Buenos Aires, 1.979). No cabe duda que el desprestigio de la democracia es un elemento importante en la explicación del surgimiento de este tipo de fenómenos. O'Donnell, por ejemplo, pone buena parte de su esperanza 
en la consolidación de las recientes democracias latinoamericanas en el hecho del prestigio ideológico que está alcanzando la democracia en estos países: «Mis esperanzas echan sus raices en un factor sutil, pero potencialmente poderoso. Se trata del hecho de que hoy en día, en la mayor parte de los países de América Latina .../... ha surgido un elemento nuevo ....... la mayoria de las fuerzas políticas $y$ culturales de algún peso atribuyen ahora un alto valor intrínseco al logro y consolidación de la democracia política» («Transiciones desde un gobierno autoritario / 2. América Latina», Guillermo O'Donnell et alii, Paidós, Barcelona, 1.994, pág. 32).

(30) Calvocoressi, Peter, «Historia política del mundo contemporáneo»: «El acercamiento de Latinoamérica al mundo exterior reflejaba las necesidades de unos países cuyas economías estaban en un proceso de transición sin recursos interiores ni maquinaria adecuados, luchando contra la mala regulación de la ayuda extranjera llevada a cabo por la generación anterior. Hacia finales del siglo XIX y en los comienzos del XX, las principales naciones capitalistas habian concedidos préstamos excesivos y con intereses muy altos a Latinoamérica, para el descontento mutuo de ambas partes: de los latinoamericanos, a los que les parecía que habian sido explotados, y de los acreedores, que se resentían por la consiguiente falta de pago ...... la xenofobia de Latinoamérica aumentó a causa de la política imperialista de los EE.UU.».

(31) Ibid., pág 563.

(32) Covo, Jacqueline, «América Latina», Editorial Acento, Madrid, 1.993, pág. 68.

(33) Gino Germani (op. cit., pág. 303-305) señala cuatro rasgos de Argentina que hacen de ella un caso "en extremo raro». El primero es la rapidez del crecimiento de la sociedad argentina, el segundo la rapidez de la modernización de la estructura social, el tercero la paralización súbita del crecimiento ocurrida durante la década de 1.920-1.930 y el cuarto rasgo se refiere, precisamente, al hecho de la fuerte corriente inmigratoria que sufre Argentina: «Argentina es probablemente el único país del mundo (salvo Israel y quizás Australia, pero son casos distintos) cuya población fuera en mayoría extranjera, y esto durante varias décadas».

(34) De la importancia de la relación de Gran Bretaña con Argentina da idea la siguiente declaración del vicepresidente de Argentina, Julio A. Roca, en su entrevista con el príncipe de Gales en el año 1.931: Argentina, «por su interdependencia recíproca, es desde el punto de vista económico, una parte integrante del imperio británico».

(35) Bagú, Sergio, «Argentina en el mundo», Fondo de Cultura Económica, Buenos Aires, 1.961, pág. 85. 
(36) Curiosamente, Gran Bretaña no estaba en absoluto interesada en que Argentina rompiera su neutralidad y se pusiera de parte de los Aliados: « $L a$ ruptura con el Eje, en cambio, no sólo interrumpiría o disminuiría esos embarques, sino que colocaría de lleno al país dentro de la órbita panamericana y apresuraria lo que ya se había iniciado penosamente: la liquidación de las inversiones británicas y su transferencia a manos estadounidenses» (ibid., pág. 90).

(37) El análisis del peronismo a partir de sus realizaciones históricas sería especialmente interesante, sobre en su contraste con el primer justicialismo y el justicialismo representado por Menem. Como dice Jacqueline Covo (op. cit., pág. 74): «Hoy, el presidente Menem, que se autoproclama peronista, ha puesto en marcha una política económica ultraliberal totalmente contraria al dirigismo y al nacionalismo que propugnaba Perón». De la misma opinión es Detlef Nolte («De 'la larga agonía de la Argentina peronista»'a la 'reconversión menemista'» en «Argentina en los 90», revista América Latina Hoy, Segunda Epoca, núms. 11-12, Diciembre-95, pág. 34): «Mientras que Perón integró los trabajadores organizados al sistema político y al modelo económico de la sustitución de importaciones, Menem resocializó de cierta manera las bases peronistas-sindicales en el nuevo modelo económico de inserción en el mercado mundial (combinado con una reducción del papel del Estado en la economía) ...... De cierta manera a través de la reconversión del Partido Justicialista, Menem logró rediseñar el mapa político de la Argentina y desplazar algunas líneas tradicionales de división y conflicto». La pregunta pertinente es: ¿Cómo algo puede ser él mismo y su contrario?, de otra manera: ¿cómo se puede ser lo mismo, lo contrario?.

(38) En este punto se ha producido una larga polémica acerca de la composición y procedencia de las bases sociales que llevaron a Perón al poder. Uno de los puntos de más discusión se refiere a la procedencia de los trabajadores que le apoyaron: si eran migrantes recientes o antiguos, si urbano o rural, etc.: «Resulta típico el juicio de Peter Ranis de que 'Perón se apoderó de los migrantes inexperimentados y no politizados, haciendo de ellos su base política'” (Eldon Kenworthy, «Sobre el apoyo inicial del peronismo» en «Desarrollo Económico», núm. 56 vol. 14, Enero-Marzo de 1.975, pág. 750). Pero entrar en esta polémica sería alejarnos demasiado del objetivo de este trabajo. Vamos a considerar simplemente que Perón fue apoyado por buena parte de la clase obrera argentina y eso no parece que ofrezca demasiada discusión.

(39) Germani, Gino, pág. 341-349, op. cit..

(40) Delamata, Gabriela, «Cultura política y espacio público en la Argentina de los años 90: una mirada sobre las identidades ciudadanas», ponencia presentada al V Congreso Español de Sociología, Granada, 28-30 de septiembre de 1.995 . 
(41) Doyon, Louise M., «El crecimiento sindical bajo el peronismo» en «Desarrollo Económico», núm. 57, vol. 15, Abril-Junio de 1.975, pág. 151153: «El crecimientó del movimiento sindical en la Argentina vivió su momento más dinámico durante la década del gobierno peronista, entre los años 1.946 y 1.955. Fue en este periodo cuando los sindicatos lograron organizar a la mayoría de los trabajadores urbanos y desarrollar en el sector moderno de la economía una vasta y compleja red de organizaciones que les permitió, aún después de la caída de Perón, continuar gravitando decididamente en la vida política del país ....... Después de que Perón fue nombrado secretario de Trabajo en octubre de 1.943, el estado alteró radicalmente su política laboral, y no sólo legitimó sino que también impulsó el rol económico y político de los sindicatos en la sociedad argentina ....... Desde la Secretaría de Trabajo se estimuló la formación de nuevos sindicatos, proveyendo la asistencia legal y técnica necesaria y concediendo atención preferencial a las reivindicaciones planteadas por organizaciones formalmente constituidas».

(42) Martínez Díaz, Nelson, pág. 16, op. cit.: «La acción social del peronismo estuvo dinamizada por la excepcional personalidad de Eva Duarte de Perón, quien no sólo desplegó una intensa labor de asistencia a los marginados, sino que llevó a cabo una inteligente relación con los sindicatos. Desde la Fundación Eva Perón, con finanzas exiguas al comienzo, que engrosaron considerablemente después, se realizó una labor de extensión social que llegaba a las regiones más apartadas de Argentina, lo que concitó una fervorosa adhesión de los sectores populares hacia la pareja Perón-Evita. El fuerte ascendiente que ejercía Evita sobre la mujer trabajadora y las que habitaban en barrios marginales, creció considerablemente con su proyecto de ley que implantaba el derecho al voto para la mujer en Argentina. A partir de ese momento, el voto femenino se convirtió en elemento eficaz para el movimiento peronista». 